\title{
LAS IDEAS LINGÜÍSTICAS EN ESPAÑA EN EL SIGLO XX
}

FRANCISCO ABAD

U.N.E.D.

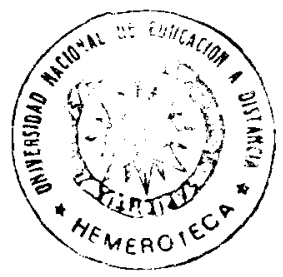

INTRODUCCIÓN

A falta de unos tres lustros para el fin de siglo parece posible ya esbozar un panorama de cuáles han sido las principales concepciones lingüísticas de la ciencia filológica española durante el mismo, y cabe - por supuesto- poder referirse a algunos de los hechos externos de mayor relieve que se han encontrado por detrás de esas ideas o concepciones sobre el idioma.

En realidad el soporte de la actividad filológica profesional lo constituye la dedicación profesoral, bien universitaria o de ensenanza media, y ocurre que el acceso a esos puestos de trabajo va a encontrarse en el más próximo futuro relativamente congelado, por lo que la nómina de profesionales de aqui a finales de la centuria se sabe ya más o menos cuál va a ser. Las líneas de trabajo de los años que vienen van a corresponder en buena lógica a desarrollos o inicios que ya se conocen, y aunque desde luego nada hay más bello que la capacidad inventiva y creadora del ser humano, el futuro cercano de los estudios lingüisticos se halla escrito al menos en sus orientaciones generales. La mayor parte de los profesionales que van a publicar lo más representativo desde ahora hasta fines de mil novecientos están trabajando ya; el pasado - por su parte- resulta conocido, y por ello puede intentarse esbozar a estas alturas de la centuria algo de lo que han sido durante la misma las ideas lingüísticas en España.

Ojalá también resulte cierto para nuestras disciplinas aquello propuesto por Ramón Tamames, quien ha querido proclamar que 
hoy, en la economía y en la sociedad, están virtualmente en investigación todos los campos, que hay multitud de investigadores trabajando, que hay resultados importantes por todas partes y que los grandes científicos del mañana están ya hoy entre nosotros '.

\section{Mexéndez Pidal}

Don Ramón Menéndez Pidal venía estando presente en la vida científica española desde 1895, cuando teniendo veintiséis años la Academia de la Lengua premió su texto, gramática y vocabulario del Cantar de Mio Cid, trabajo presentado con veinticuatro.

Diego Catalán ha advertido bien cómo por y desde entonces aquel joven "acometió calladamente la tarea heroica de poner la filología española, en sus dos ramas literaria y lingüística, en pie de igualdad con sus hermanas francesa e italiana», y cómo «aunque en un principio [sus] aportaciones en el campo de la literatura fueron sin duda las de mayor originalidad de concepción», «la edición de textos, la etimología, la gramática histórica y la dialectologian resultaron asimismo campos filológicos igualmente invadidos por él ${ }^{2}$. Por fin los tomos del Cantar de Mio Cid saldrían en 1908 y en 1911, constituyendo tales tres volúmenes de «edición tan trabajada... el primer monumentum aere perennius de la filología española» ${ }^{3}$.

Al año siguiente - no obstante- del premio académico, Menéndez Pidal publicó ya su primer opus magnum, La leyenda de los infantes de Lara ${ }^{4}$, saludado por Menéndez Pelayo como "libro magistral" en el que "el autor se ciñe sobriamente a su asunto, y llega a apurarle; pero [teniendo] el don de ver lo general en lo particular" 5 . Don Marcelino señala ya perfectamente los rasgos del trabajo monográfico y científico de Pidal: rigor en el tema tratado, sin salirse de él y acabando el análisis del mismo, más generalización teórica de los resultados obtenidos. De ningún científico de cualquier rama podría decirse nada mejor.

1 Tamames, R.: La imaginación y el poder, Barcelona, 1982, pág. 217. Sólo la invidencia a que llevan el desconocimiento o el recelo con los demás hace no darse cuenta de que, al haber aumentado el número de los estudiosos, los resultados serios tienen que aparecer también con alguna frecuencia.

2 Catalan, D.: Lingüística íbero-románica. Critica retrospectiva, Madrid, 1974, págs. 22-23.

3 Ibíd., pág. 24.

4 Tercera ed., Madrid, 1971.

5 Menéndez Pelayo, Marcelino: Estudios y discursos de crítica histórica y literaria, I, Santander, 1941, págs. 119 y 141. 
Pero Menéndez Pelayo escribía aún a propósito de La leyenda de los infantes de Lara palabras que no queremos dejar de reproducir:

Este libro excede en tal manera lo vulgar y corriente entre nosotros - dice-, que no es de admirar que no haya sido entendido por muchos y que otros le hayan despreciado sin leerle. Pero de tal desdén puede vengar ampliamente al joven autor la crítica docta y justiciera de cuantos pueden tener en Europa juicio propio sobre tan arduas materias, y esta crítica le ha sido constantemente favorable por boca de sus más autorizados intérpretes. Yo, ... no quiero dejar de unir mi voz a este concierto de justas alabanzas; porque el libro del señor Menéndez Pidal no sólo es excelente en sí mismo y admirable por la madurez de juicio que revela en los pocos años de su autor, sino todavía más admirable por el desierto intelectual en que tal obra ha nacidos.

En efecto el trabajo juvenil de don Ramón suponía que desde España se hiciese saber filológico a la misma altura que el europeo, saber que pretendía resultar rigurosa y sólidamente cientifico. El maestro coruñés empezaba a legar tanto erudición como teoría, y ello en los límites de una ciencia estricta.

Tenemos, pues, a Menéndez Pidal trabajando desde fines del siglo pasado, y con concepciones inicialmente más originales y definitivas en literatura. A La leyenda..., de 1896, seguirá luego, en efecto, el Manual elemental de gramática histórica española (1904), aún muy positivista, pero este mero positivismo empezará a ser integrado con una visión cultural de los hechos idiomáticos en el Cantar... tal como lo publica entre 1908 y 1911. Entre tanto don Ramón afianzaba sus logros crítico-literarios con «La epopeya castellana a través de la literatura española», conjunto de conferencias de 1909, y se venía dedicando también a la historiografía y a los estudios sobre el romancero.

\section{La escuela de Menéndez Pidal}

Toda esta obra propia llevada a cabo por don Ramón, que significaba -según hemos dicho- que la filología hecha en España se incorporase a la europea, iba a encontrar por fortuna respaldo institucional para su desarrollo y afianzamiento con la creación de

6 Ibid., pág. 141. 
la Junta para Ampliación de Estudios e Investigaciones Científicas y la subsiguiente del Centro de Estudios Históricos.

Aunque nosotros no concedemos al método histórico de las generaciones más alcance aclaratorio que el que muestre en cada caso concreto, de cualquier forma la ordenación de autores por grupos de edad nos parece al menos un sistema expositivo, sistema que desde luego puede llevar a veces a comprobaciones y explicaciones; vamos a enumerar por tanto, y según tales grupos de edad, a los sucesivos discípulos de don Ramón, bien entendido que nos referimos ahora $¥$ quienes han desarrollado una labor linguística de importancia, y que no mencionamos tampoco a alguno más de muerte temprana o de dedicación idiomática sólo lateral. Don Ramón y sus principales discipulos, agrupados por espacios de edad de quince años, componen esta nómina:

- Nacidos entre 1861 y 1875: Menéndez Pidal.

- Nacidos entre 1876 y 1890: García de Diego, don Tomás Navarro, Américo Castro.

- Nacidos entre 1891 y 1905: Samuel Gili Gaya, Amado Alonso, Dámaso Alonso, Salvador Fernández Ramírez.

- Nacidos entre 1906 y 1920: Rafael Lapesa.

Como puede verse, se trata de nombres coetáneos respectivamente de las llamadas generaciones literarias del noventayocho, de 1914, del veintisiete y de 1936. Además de a ellos, cabe aludir a dos miembros de la propia familia del maestro coruñés, más jóvenes y que aún alcanzaron a ser discípulos directos suyos: nos referimos a los profesores Alvaro Galmés y Diego Catalán ${ }^{7}$. En fin, discípulo a la vez de Unamuno y de Menéndez Pidal resultó ser García Blanco, a quien Rafael Lapesa se ha referido con estas palabras: "Iniciado García Blanco en las disciplinas lingüísticas -dice- por don Miguel de Unamuno en Salamanca y don Ramón Menéndez Pidal en Madrid, amplió su formación en Alemania con las enseñanzas de otros dos grandes maestros, Meyer-Lübke y Vossler... García Blanco adquirió el dominio de la metodología positivista, imprescindible en toda labor lingüística seria, y asimiló cumplidamente el impulso elevador venido de Vossler... Menéndez Pidal y su escuela del Centro de Estudios Históricos aunaban como Vossler el cultivo de la lingüística con el de la historia literaria. Así pues Alemania no supuso para

7 Profesionales de la posguerra vinculados algún momento a las tareas de don Ramón aparecen mencionados por él en las Reliquias de la poesía épica española, Madrid, 1951. 
García Blanco desvío de lo aprendido en España, sino ensanchamiento y corroboración" 8 .

Remontándonos hacia atrás, ordinariamente se ha creído que don Ramón era discípulo de Menéndez Pelayo y el montañés de Milá y Fontanals, pero Dámaso Alonso ha sabido interpretar bien cómo sólo de modo social y externo se dio en realidad tal serie de magisterios: don Marcelino es figura aparte y única en sí misma, y Menéndez Pidal deriva del Milá que escribe acerca $D e$ la poesía heroico-popular castellana ${ }^{9}$. Incluso hay que señalar que a partir de las publicaciones primeras del joven don Ramón, "el influjo de Menéndez Pidal sobre Menéndez Pelayo, es decir sobre su supuesto maestro, es evidente» ${ }^{10}$.

Concepciones de los filólogos de Madrid

Datos y testimonios recogidos ya en los párrafos anteriores nos han llevado a indicar el carácter filológico integrador de la obra investigadora de los miembros de la que también ha sido llamada "escuela de Madrid" "Volvemos ahora al sentido de tal tarea indagadora.

8 LAPESA, R.: "Manuel García Blanco", Cuadernos de la Cátedra Miguel de Unamuno, XVI-XVII, 1967, págs. 15-19.

9 Alonso, D.: «Menéndez Pidal», O. C., IV, Madrid, 1975, págs. 83-170 : páginas $85-87,101-106$.

10 Ibíd. Dámaso Alonso presenta además en estas páginas a la escuela filológica de don Ramón con párrafos que nos permiten también completar la nómina de sus discípulos citados: "Menéndez Pidal -escribe- fue durante algunos años el único lingüista moderno que tenía España. Pero pronto aparece a su lado una generación de discípulos fervorosos: Tomás Navarro Tomás..., Américo Castro, García de Diego, Solalinde... Directamente o a través de esos primeros discípulos fueron agregándose otras generaciones: Amado Alonso, Gili Gaya, Salvador Fernández Ramirez, Rafael Lapesa, Emilio Alarcos García, García Blanco, Rodríguez Castellano, Clavería, Manuel Sanchis Guarner, Sánchez Sevilla, Rosenblat, Aurelio M. Espinosa (hijo), etc... Varios de estos disćpulos de primera y segunda generación tuvieron ellos otros a su vez. La diáspora de la escuela comenzó pronto y fue luego aumentada por causas no culturales. Así se formó una subescuela de tanta importancia como la de Amado Alonso en la Argentina y en Estados Unidos... La docencia de Lapesa en la Universidad de Madrid y sus curso en universidades de los Estados Unidos han formado excelentes discípulos por todas partes. El magisterio de Solalinde dejó en los Estados Unidos una brillante escuela de editores de textos y lexicógrafos medievalistas... La escuela catalana, con nombres de generaciones diversas..., no cabe duda de que en último término es en gran parte una consecuencia del cambio que Menéndez Pidal da para toda España a estos estudios» (ibid., págs. 141-143).

il Catalán, D.: Lingüística... 
Sabido es cómo desde comienzos de siglo empiezan a surgir rectificaciones y «falsaciones» al positivismo estricto y monolítico: lingüística idealista, geografía lingüística, estudio de los aspectos sociológicos del lenguaje, lingüística sincrónica... Fueron lustros de gran esplendor para la filología románica, como testimoniaba a fines de los años cincuenta Iorgu Iordan al decir que la romanística «en cuanto a la calidad de sus obras consideradas desde el punto de vista de su importancia para las otras disciplinas linguiisticas, y especialmente para la lingüística general, hemos de reconocer que hoy no tiene ya la situación privilegiada de «directora» de las demás filologías como pude afirmar hace casi treinta años. Incluso se puede decir que se ha rezagado. No sólo desde el punto de vista de la renovación de sus propias concepciones y métodos, sino también de la asimilación de algunas de las innovaciones introducidas en la lingüística por los representantes de otras disciplinas» ${ }^{12}$. Pues bien; Menéndez Pidal supuso por su obra idiomática definitiva -la que podemos simbolizar en los Orígenes del español- la rectificación y falsación también que iba a llegar desde España al estricto positivismo neogramático. Tanto los Orígenes... como los capítulos de historia de la lengua española publicados por don Ramón, y en realidad todas sus contribuciones idiomáticas posteriores a la primera salida del Manual..., significan la integración de los datos sobre la lengua con los históricos, culturales y estéticos, de tal manera que refiriéndonos al maestro coruñés y a su escuela podemos hablar de la puesta en práctica lograda del principio de unidad de las ciencias filológicas. Se entiende que al presentar los tomos de su padre España y su historia, Gonzalo Menéndez Pidal escribiera al frente de ellos estas palabras certeras y aleccionadoras:

La linguística, la literatura, la historia cultural toda, quedan así entremezcladas en la pesquisa. Nada de invenciones o fantasías ingeniosas, por mucha fascinación que ejerzan... Los temas de lingüística, literatura e historia a muchos semejan temas inconexos, como si en la historia global de un pueblo pudiera haber departamentos estancos capaces de sobrevivir en total inconexión, siendo así que si estudiamos la lengua con amplitud de miras, la lingüística se puede volver explícita clave para comprender pasajes de la historia; igual que la reliquia histórica nos abrirá las puertas a la más gustosa contemplación de la obra de arte, a la vez que la obra poética nos puede ofrecer preciosos testimonios que ningún documento cancilleresco supo recoger ${ }^{13}$.

12 IORDAN, I.: Lingüística románica, Madrid, 1967, pág. 675.

13 MENÉndez Pidal, Ramón: España..., Madrid, 1957, I, pág. 8. No habrá esca- 
Por lo que respecta en concreto a los Origenes..., Harri Meier ha subrayado lo que tienen de ejemplo para la romanística, que espera respecto de otros idiomas obras análogas, y para la lingüística general, en tanto «manual de los principios de la historia fonética» ${ }^{14}$. En fin, desde un punto de vista cultural amplio cabe decir que don Ramón y sus discípulos, al igual que sus otros coetáneos de las generaciones del noventayocho, de 1914 y del veintisiete, se mostraron a la vez europeístas y amantes de la tradición propia, europeizadores en el método y el rigor y nacionalistas en los temas y el descubrimiento y el amor a lo propio.

Concretamos ahora las ideas de la «escuela de Madrid», según las hemos analizado y cntendido, en ocho enunciados o tesis, a saber:

1. Definición de las clases de palabras muchas veces como clases semántico-lógicas. Existencia de rangos u órdenes entre ellas.

2. Grados o continuidad en las unidades y clases: continuidad de lo lingüístico.

3. Interacción mutua entre todos los componentes (fónico, gramatical, semántico) del lenguaje.

4. La lengua como integración de una pluralidad de sistemas que coexisten; el funcionar del idioma en cuanto cambio.

5. Causa particular e historia propia de cada cambio, más gran duración en su cumplimiento.

6. Historia propia de palabras y a la vez historia propia de cada sonido.

7. La lengua como espejo de la cultura y como resultado también de la estratificación social.

8. Historia de la lengua literaria en tanto capítulo de la ciencia idiomática.

Concepciones generales así subyacen y dan sentido a las obras de Menéndez Pidal y de su escuela.

\section{DESPUÉS DE LA GUERRA}

Desde luego buena parte del trabajo de don Ramón y de sus discípulos (lo mismo que el de los poetas y prosistas coetáneos de ellos)

pado la evidente alusión desaprobadora de las interpretaciones entonces recientes de Américo Castro; en realidad, y dentro de sus compañeros de escuela, las tesis de don Américo sólo han hallado acogida favorable en don Rafael Lapesa.

14 MeIer, H.: «Ramón Menéndez Pidal y los métodos de la historia lingǘrstica», Anuario de Letras, VII, 1968-1969, págs. 43-58 : págs. 57-58. 
se cumplió tras la guerra española. Dejando ya de referirnos a Menéndez Pidal y a quienes estuvieron a su lado científicamente, desde la inmediata posguerra hasta ahora pueden distinguirse además tres generaciones sucesivas de estudiosos: son los profesionales cuya edad los agrupa en quienes nacieron de 1906 a 1920, de 1921 a 1935, y de 1936 a 1950 . Otros hay aún más jóvenes que ya han empezado a publicar, pero de momento sólo conocemos de ellos algunos nombres dispersos; los de los tres grupos de edad anteriores, en cambio, tienen un perfil científico más o menos nítido ${ }^{15}$.

La generación de mayor edad de las que citamos se ha dedicado sobre todo a la dialectología (entendida también como dialectología social), y a las filologías vasca y catalana, en las que algunos nombres de esta hornada figuran como referencias necesarias y seguras. Además, y merced al esfuerzo personal de Lapesa, este grupo de edad de estudiosos cuenta en su haber con el ensayo de una sintaxis histórica del castellano bien fundamentada. Se trata en general de filólogos que han sido testigos de muchos de los acaeceres del siglo $\mathrm{xx}$, y que han visto sus vidas determinadas en muchas ocasiones por tales sucesos; a veces por eso han escrito obra poligráfica que les ha llevado también a los textos sociopolíticos.

El grupo de estudiosos que les sigue ya hemos dicho que es el de quienes nacieron entre aproximadamente 1921 y 1935. A ellos la eclosión del estructuralismo europeo les llegó siendo a la vez suficientemente jóvenes y suficientemente maduros, por lo que creemos que se trata de la generación estructuralista en lingüística por antonomasia; en efecto se han dedicado a fonología y dialectología fonológica, fonología diacrónica, estructuralismo semántico, geografía lingüística, sociolinguística, fonética acústica, aspectos teóricos de la lengua y de la literatura...; en general, a la más variada temática de la historia de la lengua.

Es una generación en la que el ejemplo de Menéndez Pidal ha estado aún muy vigente, por lo que entre su labor no ha sido extraña la atención a la filología y a la lengua de los textos medievales o al contacto de las culturas árabe y española, al romancero, a la historiografía... ${ }^{16}$. En realidad se trata de la última generación de profesionales en la que el gusto filológico conjunto por la lengua y la literatura se halla relativamente extendido; los más jóvenes de entre ellos prefieren ya dedicarse a la sola lingüística. García Blanco y Dá-

15 Caracterizamos en lo que sigue a estas sucesivas generaciones teniendo en cuenta fundamentalmente a los romanistas más a algunos filólogos clásicos.

16 Alvaro Galmés dedica a la memoria de don Ramón uno de sus libros, advirtiendo que se ha de dar y devolver a cada uno lo suyo. 
maso Alonso fueron los maestros iniciales que aseguraron la transmisión del saber filológico a estas promociones.

En fin, queda referirse al grupo de edad más joven de estudiosos, al de los profesionales que han nacido más o menos entre 1936 y los tres lustros siguientes. Algunos de los mayores de ellos cuentan ya con reconocimiento cierto, mientras que el núcleo más joven —que es más numeroso- ha escrito sus obras iniciales y juveniles y empieza quizá ahora a dar los resultados más maduros.

Se trata de profesionales que en su mayor parte ya no tienen a Menéndez Pidal como modelo y entre quienes la dedicación filológica integradora es más rara: el porcentaje de lingüistas y de filólogos en esta hornada es aproximadamente el contrario del que se da en la anterior, que es - por otra parte- la que la ha formado. Entre sus preferencias temáticas se encuentran la gramática sincrónica (bien más clásica o de orientación norteamericana), a veces la diacronía - tanto fonética como gramatical o léxica-, el estudio de la lengua literaria y de la prosa, y el interés por la historia de las ideas lingüísticas y de la teoría literaria.

Para estos autores, dados los años que van teniendo ya, empieza a llegar la hora de la verdad; hacia finales de siglo habrán mostrado cuál es la medida de su talla. En la España de las autonomías pueden contar (aunque no todos) con ciertos medios de trabajo: en efecto, según el gobierno regional del que se dependa y según la temática a que uno se dedique, resulta o no más fácil recibir ayuda en forma de becas para el extranjero, compra de material, subvención de publicaciones, $y$ cien actividades más.

OBSTÁculos PaRa el DESARRollo

DE LOS ESTUDIOS LINGÜISTICOS

El progreso en el conocimiento de las materias filológicas tiene limitaciones que surgen de las propias del ser humano, que son tanto científicas como de orden meramente personal; vamos a referirnos ahora a cuatro clases de ellas.

a) La información disponible desborda de tal manera la capacidad de cualquier estudioso que quizá por ello la comunidad profesional se ha vuelto un poco crispada y dogmática; ocurre desde luego en todos los países. Parece que como cada uno sabe de lo que entiende, achaca su ignorancia a los demás, y esta situación un poco crispada lleva en definitiva a estar cerrados a sugerencias y pistas que a veces nos llegan. 
Por supuesto la inflación y el desorden terminológicos complica más las facilidades para entenderse y enriquecerse mutuamente.

b) Ligada a la capacidad finita para estar informados se halla una autolimitación más perezosa: uno se especializa y olvida los terrenos limítrofes, cuando la verdad es que distintos problemas nos piden si queremos aclararnos que tengamos a la vez en cuenta el punto d $\epsilon$ vista de diversas disciplinas; a esto alude el dicho de que "toda ciencia avanza por sus fronteras", esto es, que muchas veces se entienden y aclaran las cosas cuando se las contempla desde distintas perspectivas relacionadas entre sí.

Personalmente creemos - por ejemplo- que varios testimonios de Nebrija, de Juan del Encina y de Juan de Valdés no llegarán a entenderse si no se tiene en cuenta la revolución literaria que supuso Garcilaso, y desde luego lo mismo puede decirse al contrario. $\mathrm{O}$, por poner un segundo caso, sólo entenderá las contribuciones lingüísticas de don Gregorio Mayans quien de verdad se asome al menos a la trayectoria y circunstancias de su vida y de su pensamiento todo.

Tanto por la abundancia de materiales de trabajo como por la necesaria conexión en que han de ser puestos, cabe repetir con Lapesa que, en efecto, existen "infinitas monografías, artículos y notas cuyas aportaciones reclaman criba y coordinación" ${ }^{17}$.

c) El progreso en el conocimiento de algunas áreas parece estar limitado por el menor número de estudiosos que se dedican a ellas, mientras en otras quizá se sabría lo mismo aunque el número de sus profesionales resultase menor; «apena pensar -escribía Manuel Alvar hace unos años- en cómo tenemos a nuestra literatura medieval o a nuestra historia de la lengua" ${ }^{18}$. Ciertamente el número de filólogos es muy grande y hoy día se trabaja en todos los terrenos, pero a veces cabe preguntarse si la teorización indefinida no acaba por ser academicismo un poco estéril.

d) En fin, distorsiona la realidad del estado de la investigación y su conocimiento el solo trabajar con lo que está más a mano y resulta más canónico y establecido, el elogio por el elogio o el rechazo por el rechazo, el etiquetado abusivo de escuelas y tantas otras limitaciones que al investigador en cuanto personal le acechan. Alguna vez hemos recogido ya un par de párrafos que vamos a volver a citar aquí: "En investigación -escribe Erich von Richthofen-, aparte de seguir dócilmente lo que está en vogue, sólo encontramos

17 LAPESA, Rafael: "Sobre problemas y métodos de una sintaxis histórica», Homenaje a Xavier Zubiri, Madrid, 1970, II, págs. 201-213: pág. 202.

18 Alvar, M., ed.: Libro de Apolonio, Madrid, 1976, I, pág. 18. 
escasos ejemplos de admiración de unos estudiosos hacia otros que sobresalen en ciertos terrenos o aspectos..., y demasiado pocos investigadores consiguen distinguirse por aunar desacuerdo y respeto"19. Por otra parte, también se ha dicho que "al colega o se le bombea o se le empluma, pero más bien por razones de índole personal" ${ }^{20}$.

FINAL

El futuro se halla siempre abierto, aunque desde luego determinado en parte por lo que ya ha sucedido. En general, y también por lo que respecta a las ciencias filológicas, queremos creer con las palabras optimistas de Tamames que hoy están virtualmente en investigación todos los campos, que hay multitud de investigadores trabajando y que resulta inevitable por tanto que haya resultados importantes.

De aquí a fines de la centuria, las áreas de trabajo en lingüística y las concepciones derivadas de ellas que mayor vigencia alcancen nos parece que, entre nosotros, serán las que ya caracterizan a las varias generaciones de profesionales que hemos distinguido. Todos sus miembros se encuentran suficientemente "hechos" como para que suceda otra cosa.

En pocas palabras, podemos decir que la teoría lingüística española de nuestro siglo ha contado a comienzos del mismo con una figura de excepción, la de Menéndez Pidal, cuyo ejemplo de ámbitos y modo de trabajo se ha extendido más allá de él hasta cuatro generaciones sucesivas de estudiosos. En la historia de la cultura contemporánea a las promociones o generaciones a las que pertenecen los filólogos hispanos se las conoce como las del 98, del 14, del 27 y del 36; quedan otras dos más, a las que los profesionales de la literatura empieza a llamar "la generación del medio siglo», esto es, la de los años cincuenta, y «la generación del 68»: se trata de las que nosotros hemos identificado porque sus miembros nacen a partir de 1921 y $1936^{21}$.

19 Limites de la critica literaria, Madrid, 1976, pág. 59.

20 Cataldan, D.: Lingüística...; comp. nuestra Caracterización de la literatura española, Madrid, Tapia, 1983, págs. 23-24.

${ }^{21}$ Redactado este artículo antes de salir la Literatura actual de Santos Sanz Villanueva (Barcelona, 1984), vemos que coincidimos con él en el deslinde de estos dos últimos grupos de edad entre los creadores de cultura. Asimismo podrá notarse que las presentes páginas han sido concebidas desde una disposición que es la misma que el profesor Santos Sanz describe en su prólogo, al que pertenecen los siguientes párrafos con los que estamos identificados: "Creo que 
El modo de trabajo de don Ramón ya no es un modelo ideal más o menos implícito o explícito para la hornada más joven de estudiosos, de los cuales tampoco se pueden decir muchas cosas porque muchos de ellos aún no han tenido tiempo más que de hacer su obra de juventud.

En este 1984 en que escribimos somos optimistas respecto de lo que aún vayan a hacer todos los profesionales que trabajan en linguística de entre nosotros; a veces en cambio nos llega el pesimismo: la falta de información o de formación, la pequeña y frecuentísima trapacería de citar como si se hubiese leído lo que se cita, la falta de reconocimiento al acierto que haya en el trabajo de los demás o el elogio desmedido de lo que no lo merece, la seguridad falsamente firme en el propio saber, etc., a todos los estudiosos nos acechan en cuanto somos personas. Quede dicho - desde luego- en primer lugar como autocrítica ${ }^{2}$.

los criterios generacionales, planteados con flexibilidad y prudencia, describen con bastante propiedad los movimientos culturales, y se observará... cómo coinciden actitudes éticas y principios literarios en gentes de edades próximas que han tenido semejante formación y han sentido parecidas inquietudes [...] La imparcialidad no es una categoría crítica sino moral, y de ella sí que respondo [...] Decía Clarín que en España no había crítica literaria, sino sociedades de bombos mutuos. La situación no ha cambiado mucho un siglo después [...] La balumba de monografías hipergenerosas y sobre todo acríticas que surcan las páginas de las revistas del hispanismo... produce grandes distorsiones en la valoración de un escritor.n

22 Es muy bello el ejemplo (por poner un caso) de don Salvador Fernández Ramírez, de quien ha podido decir Lapesa: "Su bondad le hacía confiar demasiado en la ajena, y su desinterés por el provecho material lo mantuvo libre de ambiciones [...] No se pavoneo en las ferias de la vanidad.» Vid. LAPESA, R.: *Salvador Fernández Ramírez», B. R. A.E., LXIII, 1983, págs. 15-28. 